\section{Potential Constants of Tetrachlorethylene}

G. B. B. M. Sutherland and D. M. Dennison ${ }^{2}$ have deduced the relations between the parallel frequencies and the potential constants of the ethylene molecule from a given potential function; the following deals with the extension of these relations to a similar type of molecule, namely, that of tetrachlorethylene.

If from the data on Raman and infra-red spectra ${ }^{2}$ we assume for the frequencies (Sutherland's notations) :

$\nu_{1}=913 \mathrm{~cm}^{-1} ; \quad \nu_{2}=445 \mathrm{~cm}^{-1} ; \quad \nu_{3}=345 \mathrm{~cm}^{-1} ;$ $\nu_{4}=1569 \mathrm{~cm}^{-1} ; \quad \nu_{8}=236 \mathrm{~cm}^{-1}$

and substitute these values in equation $(a)$

$$
\nu_{1}^{2}+\nu_{3}^{2}+\frac{M+2 m}{M} \frac{\nu_{2}^{2} \nu_{4}^{2} \nu_{8}^{2}}{\nu_{1}^{2} \nu_{3}^{2}}=\nu_{2}^{2}+\nu_{4}^{2}+\nu_{8}^{2}
$$

which has been deduced from the potential function, we obtain satisfactory agreement.

However, before computing the potential constants, it is necessary to modify the experimental values of the frequencies in order to satisfy equation $(a)$ exactly.

A least square solution gave :

$$
\begin{aligned}
& v_{1}^{*}=913 \mathrm{~cm}^{-1} ; v_{2}^{*}=442 \mathrm{~cm}^{-1} ; v_{3}^{*}=345 \mathrm{~cm}^{-1} ; \\
& v_{4}^{*}=1569 \mathrm{~cm}^{-1} ; v_{8}^{*}=230 \mathrm{~cm} .^{-1} .
\end{aligned}
$$

The smallness of the change of the experimental frequencies sufficient to verify equation $(a)$ exactly should be noted.

Finally we find :

$a=4 \cdot 59 \times 10^{5}$ dynes $/ \mathrm{cm}$. $b=1 \cdot 89 \times 10^{5} \mathrm{dynes} / \mathrm{cm}$. $c=6 \cdot 15 \times 10^{5}$ dynes $/ \mathrm{cm}$. $d= \pm 1.52$ dynes $/ \mathrm{cm}$.

$a, b, c, d$ being the potential constants.

The difference between my value of $c(\mathrm{C}-\mathrm{C}$ bond) and Sutherland and Dennison's value for ethylene $\left(9.79 \times 10^{5}\right.$ dynes/cm. $)$ is very remarkable. For this reason, $\mathrm{I}$ also used the Delfosse potential function ${ }^{3}$, which is absolutely independent of Sutherland and Dennison's. Furthermore, I used only the three Raman frequencies $v_{2}, v_{4}, v_{8}$, which are much more certain than the $\nu_{1}$ and $v_{3}$ necessary in Sutherland and Dennison's theory. This ought to give more weight to the following results.

We find :

$F^{\prime}=6 \cdot 25 \times 10^{5}$ dynes $/ \mathrm{cm}$. $\gamma=2 \cdot 24 \times 10^{5}$ dynes $/$ cm. ; $f=1 \cdot 28 \times 10^{5}$ dynes $/ \mathrm{cm}$.

$f$ and $F$ are respectively proportional to the $\mathrm{C}-\mathrm{Cl}$ and $\mathrm{C}-\mathrm{C}$ distances ; $\gamma$ is a force proportional to the angle variation $\mathrm{Cl}-\mathrm{C}-\mathrm{Cl}$.

The agreement between the two values of the $\mathrm{C}-\mathrm{C}$ strength bond is very striking. It should be noted that the value $\gamma$ is greater than $f$. This is contrary to ordinary chemical conceptions. The difference between the C-C value for ethylene and tetrachlorethylene agrees qualitatively with Badger's formula ${ }^{4}$

$$
r_{e}^{\cdot}=\left(C_{i j} / k_{e}\right)^{1 / 3}+d_{i j}
$$

which shows a very definite relation between the force constant $k_{e}$ for a particular bond and the internuclear distance $r_{e}$ associated with that bond. Consequently, if the force constant is smaller in $\mathrm{C}_{2} \mathrm{Cl}_{4}$ than in $\mathrm{C}_{2} \mathrm{H}_{4}$, the $\mathrm{C}-\mathrm{C}$ distance should be larger in $\mathrm{C}_{2} \mathrm{Cl}_{4}$ than in $\mathrm{C}_{2} \mathrm{H}_{4}$. Electronic diffraction and spectroscopic measurements do not invalidate this deduction. L. O. Brockway gives 1.38 A. for tetrachlorethylene, W. Scheib and P. Lueg ${ }^{6}$ 1.34 A. for ethylene. The C-C distance deduced from
Badger's formula is too small. However, Penney and Sutherland ${ }^{7}$ have shown that considerable divergences exist from the formula in other compounds.

If the force constant is real, its variation might be due to the fact that tetrachlorethylene is a combination of molecules showing quite different structures, as for example:<smiles>ClC(Cl)=C(Cl)Cl</smiles>

In that case, the $\mathrm{C}-\mathrm{C}$ value would be a sort of resonance between the double and single bonds.

These considerations do not, however, exclude the possibility that this molecule cannot be treated in the same way as $\mathrm{C}_{2} \mathrm{H}_{4}$.

In the preparation of this note, I am especially indebted to Prof. V. Henri for his personal attention, and to Dr. G. B. B. M. Sutherland for correspondence.

Department of Physical Chemistry, JuLes DuChesne. University, Liège.

1 Sutherland, G. B. B. M., and Dennison, D. M., Proc. Roy. Soc., A, 148, 250 (1935).

'Landolt-Börnstein Tables, 992 and 995 ; Ta-You-Wu, Phys. Rev., 46, 465 (1934).

'Delfosse, J. M., Ann. Soc. Sci. Brux., 55, 114 (1935).

- Badger, J. Chem. Phys., 3, 710 (1935).

- Brockway, L. O., Rev. Mod. Phys., 8, 261 (1936).

- Scheib, W., and Lueg, P., Z. Phys., 81, 764 (1933).

'Penney, W. G., and Sutherland, G. B. B. M., Proc. Roy. Soc., A, 156, 676 (1936).

\section{Raman Spectra of Oxonium Compounds}

The study of the Raman spectra of oxonium compounds is of interest for the elucidation of the nature of the oxonium bond. Such a study was made by Briegleb and Laupp ${ }^{1}$, who investigated the spectra of mixtures of ethyl ether with hydrogen bromide and stannic chloride. However, their work does not give a clear and unequivocal answer to the question of the nature of such compounds. We have under. taken the study of the oxonium molecule $\left(\mathrm{CH}_{3}\right)_{2} \mathrm{O} . \mathrm{HCl}$, which is known to exist even in the gaseous state. The equilibrium between methyl ether and hydrogen chloride has been studied in the vapour state with sufficient exactness ${ }^{2}$. It cannot be doubted, therefore, that $\left(\mathrm{CH}_{3}\right)_{2} \mathrm{O} . \mathrm{HCl}$ exists as an individual molecule, We have obtained for $\left(\mathrm{CH}_{3}\right)_{2} \mathrm{O}$ in the liquid state, at $280^{\circ} \mathrm{K}$., the following frequencies : $408(2)(e, k)$; $921(6 d)(e, k, i) ; 1095(1)(k) ; 1448 \quad(2 d)(e, k)$; 2813 (10) $(e, k, q, p) ; 2868$ (3) $(e, k, i) ; 2908$ (3) $(e, k, q) ; 2947(2)(e, k, q) ; 2988(6)(e, k, q, p)$.

These data agree well with the results of Kohl. rausch $^{3}$. We have investigated the spectra of equimolecular mixtures of methyl ether, $\left(\mathrm{CH}_{3}\right)_{2} \mathrm{O}$, and hydrogen chloride at $280^{\circ} \mathrm{K}$. in the liquid state. We obtained the following frequencies: $418(3)(k)$; $891(4 d)(e, k) ; 1081(1)(k) ; 1449(1 d)(e, k) ; 2829$ (7) $(e, k, q) ; 2875(2)(e, k) ; 2923(2)(e, k, q, p) ; 2953$ (2d) $(e, k, i) ; 3003(5 d)(e, k, q)$.

The same mixture was investigated at low tempera. tures down to $220^{\circ} \mathrm{K}$. No shift at all could be observed in comparison with the spectra at $280^{\circ} \mathrm{K}$. The comparison of the spectra of $\left(\mathrm{CH}_{3}\right)_{2} \mathrm{O} . \mathrm{HCl}$ with the spectra of $\left(\mathrm{CH}_{3}\right)_{2} \mathrm{O}$ shows the absence of new lines. It may, however, be stated that displacements were noticed in a series of frequencies that were greater than the error of the experiments $\left(\sim 5 \mathrm{~cm} .^{-1}\right)$. Of the greatest interest is the decrease of the frequency 